\title{
REFERENCES
}

1. Averintsev, S. (2004) Poetika rannevizantiyskoy literaturyi. S.-Pb. : Azbuka-klassika.

2. Ilin, I. (2004) Osnovyi hristianskoy kulturyi. S-Pb. : Shpil.

3. Sv. prav. Ioann Kronshtadskiy. (2004) Myisli o bogosluzhenii Pravoslavnoy Tserkvi. «Moya zhizn vo Hriste». M. : Russkiy Hronograf.

4. Florenskiy, P. (2001) Pravoslavie // Hristianstvo i kultura. M. : Ast.

5. Florenskiy, P. (2001) Troitse-Sergieva Lavra i Rossiya // Hristianstvo i kultura. M.: Ast.

6. Florenskiy, P. (2004) Filosofiya kulta. M. : Myisl.

7. Florenskiy, P. (2001) Hramovoe deystvo kak sintez iskusstv // Hristianstvo i kultura. M.: Ast.

Стаття надійщла до редакції 15.06.2016

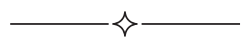

УДК 78.03+78.082.2/786.2

Юлия Александровна Грибиненко, кандидат искусствоведения, доцент кафедры истории музыки и музыкальной этнографии

Одесской национальной музыкальной академии им. А. В. Неждановой j.a.g@ukr.net

\section{ИНДИВИДУАЛЬНО-АВТОРСКИЙ АСПЕКТ СТИЛЕВОГО СИНТЕЗА В ФОРТЕПИАННЫХ СОНАТАХ В. СИЛЬВЕСТРОВА}

Целью работы является рассмотрение путей и способов реализации стилевых взаимодействий в фортепианных сонатах Валентина Сильвестрова, а также определение индивидуально-авторского аспекта стилевого синтеза как отражения концепции «интонируемого мироощущения» во второй половине XX века. Методология: в работе применены историографический, жанрово-номинативный и аналитический музыковедческий подходы. Научная новизна работы заключается в расширении представлений об имманентных свойствах композиторского стиля B. Сильвестрова, в определении типичных особенностей полистилистики в его творчестве. Выводы. В композиторской поэтике В. Сильвестрова мы находим убедительный пример полистилистики, требующий появления новой номинации, поскольку он не укладываются ни в один из известных ее типов. Исходя из своеобразия индивидуальной композиторской поэтики, предлагаем определять полистилистику В. Сильвестрова как

(C) Грибиненко Ю. А., 2016 
центробежную. Эта номинация существенно проясняет творческий метод композитора, загадка которого заключается в том, что В. Сильвестров не столько создает дистанцию между «своим» и «чужим», сколько пытается подойти к последнему ближе, стремится в этом диалоге найти новую близость, новую ступень тождества.

Ключевые слова: фортепианная соната, полистилистика, стиль, центробежная полистилистика, ослабленная динамика, сонорность.

Grybynenko Julia, Ph.D. in the History of Art, assistant professor of the department of music history and musical ethnography of Odessa National A. V. Nezhdanova Academy of Music

\section{Individual-author aspect of style synthesis in piano sonatas $V$. Silvestrov}

The purpose of work is to examine ways and means of implementing style interactions in Valentine Silvestrov's piano sonatas, as well as defining the individual and author's aspect of style synthesis as a reflection of the concept of an «intuited worldview» in the second half of the twentieth century. Methodology: historiographic, genre-nominative and analytical musicological approaches are applied in the work. Scientific novelty of the work is to broaden the notion of the immanent properties of $V$. Sylvestrov's compositional style, in defining typical features of polystylistics in his work. Conclusions. In the composer poetics of $V$. Silvestrov, we find a convincing example of polystylistics, which requires the appearance of a new nomination, since it does not fit into any of its known types. Proceeding from the peculiarity of individual composer poetics, we propose to define the polystylistics of $V$. Silvestrov as centrifugal. This nomination essentially clarifies the composer's creative method, the riddle of which lies in the fact that $V$. Sylvestrov not so much creates a distance between "one's own» and «another's» as he tries to approach the latter closer, strives in this dialogue to find a new affinity, a new stage of identity.

Keywords: piano sonata, polystylistics, style, centrifugal polystylistics, weakened dynamics, sonority

Грібінснко Юлія Олександрівна, кандидат мистецтвознавства, доцент кафедри історії музики та музичної етнографії Одеської національної музичної академії ім. А. В. Нежданової

Індивідуально-авторський аспект стильового синтезу у фортепіанних сонатах В. Сильвестрова

Метою роботи є розгляд шляхів та способів реалізації стильових взаємодій у фортепіанних сонатах Валентина Сильвестрова, а також визначення індивідуально-авторського аспекту стильового синтезу як відображення концепції «інтонуємого світовідчуття» у другій половині ХX століття. Методологія: в роботі застосовані історіографічний, жанрово-номінативний $і$ аналітичний музикознавчий підходи. Наукова новизна роботи полягає в розширенні уявлень про іманентні властивості композиторського стилю В. Сильвестрова, у визначенні типових особли- 
востей полістилістики в його творчості. Висновки. У композиторській поетиці В. Сильвестрова ми знаходимо переконливий приклад полістилістики, що вимагає появи нової номінації, оскільки він не вкладається ні в один з відомих їі типів. Виходячи зі своєрідності індивідуальної композиторської поетики, пропонуємо визначати полістилістику В. Сильвестрова як відиентрову. Ця номінація істотно прояснюе творчий метод композитора, загадка якого полягає в тому, що В. Сильвестров не стільки створює дистанцію міже «своїм» $i$ «чжии», скільки намагається підійти до останнього ближче, прагне в иьому діалозі знайти нову близькість, новий щабель тотожності.

Ключові слова: фортепіанна соната, полістилістика, стиль, відцентрова полістилістика, ослаблена динаміка, сонорность

Актуальность темы исследования. Одной из ведущих тенденций современного композиторского творчества становится развитие полистилистики в сторону стилевого синтеза и моностиля, что, в свою очередь, можно рассматривать как своеобразную победу авторского стиля над полицентризмом исторического музыкального сознания. Полистилистика в XX столетии осознается как универсальный метод композиторского творчества; в то же время каждый из современных авторов находит свой путь к полистилистике, выстраивая особые художественные отношения с ней. В фортепианных произведениях Валентина Сильвестрова - создателя уникального музыкального стиля - эти аспекты находят оригинальное воплощение.

Анализ исследований и публикаций. Проблематика данной работы обусловила обращение, прежде всего, к исследованиям, освещающим специфику композиторского стиля В. Сильвестрова. Среди них труды О. Билык [1], Д. Жалейко [2], Е. Зинькевич [3], С. Павлишин [8], И. Коханик [4; 5], А. Сальм [9]. Существенную роль сыграли и опубликованные интервью композитора, дающие представление о мировоззрении В. Сильвестрова, его эстетических приоритетах. Это книга, составленная С. Пилютиковым, «Дождаться музыки» [11], беседы композитора с М. Нестьевой [7; 10], А. Луниной [6] и т. д. Отдельно отметим также, что фортепианные сонаты В. Сильвестрова в контексте заявленной проблематики исследованы недостаточно: частично данного аспекта касаются авторы авторитетных монографий и научных статей, такие как В. Холопова [13; 14], Е. Чигарева [12] и др.

Целью данной статьи является рассмотрение путей и способов реализации стилевых взаимодействий в фортепианных сонатах Валентина Сильвестрова, а также определение индивидуально-авторского 
аспекта стилевого синтеза как отражения концепции «интонируемого мироощущения» во второй половине XX века.

Изложение основного материала. Обращение В. Сильвестрова к жанру сонаты для фортепиано нельзя назвать частым и постоянным. Первые произведения в этом жанре были написаны композитором еще в период обучения в консерватории - в начале 1960-х годов. Это сонатина, Классическая соната и первая соната для фортепиано. В 1975 и 1983 годах были созданы вторая и третья фортепианные сонаты. Таким образом утверждать, что фортепианная соната является неким «сквозным» жанром творчества В. Сильвестрова, как, например, это было у Г. Уствольской (ее шесть сонат охватывают более чем сорокалетний период с 1947 по 1988 год) либо у Б. Тищенко (одиннадцать сонат для фортепиано этого композитора хронологически ограничены 1957 и 2008 годами), невозможно. Однако обратим внимание при этом, что именно фортепианная (камерно-инструментальная) сфера становится своеобразным тезаурусом стилистических особенностей, ключевых авторских слов и констант логики композиторского мышления В. Сильвестрова, именно в ней формируется то, что впоследствии станет важной и необходимой составляющей, например, для симфонической музыки композитора.

Действительно, произведения камерного жанра занимают в творчестве В. Сильвестрова одно из ведущих мест. Среди них: часто исполняемые квинтет для двух скрипок, альта, виолончели и фортепиано, два струнных квартета, Драма для скрипки, виолончели и фортепиано (две из трех частей этого произведения являются сонатами), постлюдия для виолончели и фортепиано, постлюдия DSCH для сопрано, скрипки, виолончели и фортепиано и многие другие произведения для камерного оркестра. Отметим, что сонатный жанр у В. Сильвестрова представляют также написанная им в 1983 году соната для виолончели и фортепиано с посвящением Ивану Монигетти и созданная в 1990 году соната для скрипки и фортепиано со знаковым для творчества композитора названием «POST SCRIPTUM».

Выбор в качестве центральной дефиниции данного исследования фортепианной сонаты во многом объясняется и той творческой задачей, которую сам композитор ставит перед собой в рамках этого жанра. По словам В. Сильвестрова в 1960-1970-е годы одной из центральных проблем в его творчестве (и не только его) было, прежде всего, желание найти единство всех музыкальных систем, преодоление антагонизма между старым и новым. Одним из первых произ- 
ведений, в которых находит особое воплощение заявленное, стала «Медитация», симфония для виолончели и камерного оркестра. Однако, по замечанию композитора, наличие относительно большого оркестра, разнообразие музыкально-выразительных средств предоставляло возможность множества путей для воплощения полистилистической композиции. Это и послужило причиной следующих рассуждений В. Сильвестрова: идея нового единства только тогда «покажет себя жизнеспособной, когда тоже самое можно будет сделать и для одного инструмента» [11, 87-88]. В результате именно фортепианные сонаты композитора становятся своеобразным экспериментальным полем для решения поставленных автором задач в русле полистилистических тенденций, актуальных для композиторов второй половины XX века.

Первая соната была написана В. Сильвестровым в период становления композиторского стиля. В ней привлекает внимание авторское видение доклассической и классической музыки. Это наиболее традиционная и привычная из всех сонат композитора. Известно, что создавалось она под впечатлением трагической судьбы близкого друга, исполнителя его произведений Станислава Вередина, которому собственно и посвящен опус.

В сонате сочетаются сосредоточенная психологическая углубленность и сокровенность тона высказывания, импровизационность тематического изложения с «тотальной» мелодичностью, которая пронизывает всю фортепианную фактуру, выстроенную по принципу «... распевания как способа интонирования» $[7,90]$.

В этом произведении используется принцип чередования и возвращения (повторения) основных тематических разделов, каждый из которых обладает своими жанрово-стилистическими признаками. Наиболее яркий из возможных жанровых прототипов - вальсовый: побочная партия I части - вальс - представляет собой измененный вариант темы вступления. Он связан с достаточно плавным и бесцезурным мелодическим движением, а также с общей динамикой «озвученного молчания». Как контрастный по темпу, громкостной динамике, способу артикуляции эпизод Allegro сопряжен с появлением пунктирного ритма, мелких ритмических длительностей, триольных построений, с более широким охватом фактуры.

Вторую часть открывает созвучие-заглавие: трезвучие с пропущенной терцией, изложенное целой длительностью на pp. Песенная простота мелодического контура и преобладание трезвучных гармо- 
ний отражают характер «dolchissimo», господствующий в этой части, а также динамически приглушенную, подчеркнуто камерную повествовательность интонаций.

Вторая фортепианная соната открывает один из самых значительных периодов творчества композитора, для которого характерно усиление лиричности, эмоциональности, а также господство в музыкальном языке тональных и модальных элементов. Так же как и предыдущая, данная соната имеет посвящение. Написанная в 1975 году, она посвящена первому ее исполнителю - Алексею Любимову, который уже вошел в музыкальную историю как один из лучших интерпретаторов творчества В. Сильвестрова.

В этом произведении автор, по мнению С. Павлишин, выступает «прямым продолжателем лирической линии, созданной Ф. Шубертом» $[8,51]$, несмотря на безусловную современность музыкального языка. Здесь ориентиром для В. Сильвестрова становится прежде «неактуальная» романтическая стилистика. Единым для всей сонаты также становится постепенное формирование в недрах атональной системы широкой тональной кантилены, наличие импрессионистически разряженной прозрачной музыкальной ткани с тонкой рафинированной динамической нюансировкой, пространственность звучания, новая красочность, обусловленная тембрально-регистровым фактором и приводящая к сонористике [2]. Все перечисленное станет впоследствии одной из основ интонационного словаря последующих произведений В. Сильвестрова.

Вторая соната обращает на себя внимание сдвигом в сторону быстрых темпов, а также ощутимыми колебаниями темпов внутри своей одночастной композиции. Форму данной сонаты можно было бы назвать поэмной, но с оговоркой, что «поэмность» В. Сильвестров понимает скорее по-шопеновски, чем по-листовски. У Ф. Шопена это гиперболизированная миниатюра, которая в силу появившихся в ней контрастов обнаруживает сходство с циклом.

Композиция сонаты строится на диалогическом сопоставлении декламационности и общих форм движения, контрастном противопоставлении полетности и выдержанных звучаний. Логический результат взаимодействия этих элементов приводит к появлению в разработочном разделе выдержанного хорала и сонорных звучаний.

Особое внимание на себя обращает разнообразие исполнительских приемов сонаты, которые композитор, подробно объясняя, выписывает в нотах, все они становятся неотъемлемой частью стилевой 
системы В. Сильвестрова. Это и обильная педализация музыкальной ткани сонаты с авторским уточнением глубины педали (композитор выделяет три уровня педали, обозначая их $1 / 2,1 / 3$ ), и различное исполнение кластерных созвучий ударом кулаками, ребром руки, костяшками пальцев, подушечками пальцев, ногтями, и беззвучное нажатие клавиш, и удары по струнам и т. д. Все перечисленное обогащает музыкальную ткань обертоновыми отзвуками, создавая особое звучащее пространство. Отмечая данное качество сонаты В. Сильвестрова, М. Нестьева отмечает, что одна из важных задач интерпретатора, артиста, играющего и поющего сочинения композитора, «уловить и донести до слушателя ту духовную ауру, которая породила сочинение и лишь частично материализовалась в нотах, словно оставшись неким ощутимым следом подтекста в фиксированной записи» $[10,66]$.

Следующую третью фортепианную сонату Валентин Сильвестров посвятил украинскому дирижеру, руководителю Национального ансамбля солистов «Киевская камерата» Валерию Матюхину. Именно под его управлением состоялось премьерное исполнение произведений многих украинских композиторов, в том числе и Валентина Сильвестрова. Написанная в 1979 году, на данный момент третья соната является заключительным образцом этого жанра в творчестве композитора.

Для третьей фортепианной сонаты, созданной в период творческой зрелости В. Сильвестрова, характерно объединение своеобразной импровизационности и структурной четкости. О. Билык определяет форму данного произведения как «форму-состояние, статический процесс» с ярко выраженной симметричностью разделов [1].

Во всех частях сонаты - Прелюдии, Фуге и Постлюдии - наиболее частым знаком громкостной динамики становится ppp, а к ремаркам «dolchissimo», «legatissimo» присоединяется обозначение «leggierissimo». Кроме того, здесь обращает на себя внимание отношение В. Сильвестрова к феномену звука в принципе. Все фазы звучания в сонате подробно дифференцированы через динамические указания. Для композитора важен каждый этап «жизни» звука. Отмечая знаком ritenuto начало, середину или заключительную фазу, композитор сознательно стремится «удержать» звук, внимательнее его дослушать, проконтролировать все этапы его развертывания.

В данной сонате господствуют новые типы интонирования, связанные с дискретностью фактуры, неповторяемостью звуков мелодии, придающие ей сходство с серией. Из жанровых ориентаций 
в цикле можно назвать этюдно-прелюдийную фактуру, хорал в соединении с декламационной экспрессией горизонтального мелодического контура, но полностью погашенной, однако, средствами «тихой динамики». Отметим пристрастие В. Сильвестрова к пунктирным, триольным фигурам, которые не могут не вызвать определенной аналогии с «танцевально-полетными» образами А. Скрябина.

Большое значение в сонате имеют средства сонористической выразительности как указание на актуализированную, бесцеремонно врывающуюся в человеческую жизнь, агрессивную по отношению к ней, внешнюю действительность.

В результате представленных аналитических рассуждений в сонатных циклах можно обнаружить следующие особенности полистилистического метода В. Сильвестрова:

- серийные, пуантилистические и сонорные способы организации музыкальной ткани расширяют свой смысловой диапазон, оказываются способными «нести» с собой не только актуально-агрессивное, но и «мир тишины», «озвученного молчания», которые чаще всего у В. Сильвестрова связаны со стилизацией и обращением к «устаревшим фонемам», которые произносит как свои;

- импровизационность изложения музыкального материала, сочетающаяся с продуманной, четкой организацией всех структурных элементов;

- ослабление динамики - и буквально громкостной, и смысловой - как способ указать на авторское присутствие в материале. В сонатах В. Сильвестров стремится еще больше углубить область «тихой динамики» (эта область, несомненно, превалирует в его фортепианных сочинениях);

- выстраивание драматургии сочинений, прежде всего, с помощью средств звуковой палитры;

- усиление сонористической свободы и в целом свободы от какой бы то ни было определенной жанровой адресованности музыки связано с появлением новых исполнительских знаков и, шире, новой манеры обращения композитора к исполнителю;

- стремление к одночастности, композиционной сжатости. В камерных сонатах В. Сильвестрова наблюдаются, с одной стороны, стремление к лаконичности и концентрированности формы; с другой - сложные интонационно-стилевые и образные взаимодействия, указывающие на масштаб и концептуальность мышления в данном жанре; 
- превалирование замедленных темпов, открытие сонатных композиций медленной частью позволяет усмотреть в этом своего рода рефлексию композитора второй половины XX века на тему самого жанра сонаты: он воспринимается и преподносится как принципиально серьезный, концептуальный;

- психологическая самоуглубленность, интроспективность [2], переходящая в медидативность, присуща всем трем фортепианным сонатам композитора, образный строй которых он трактует в лирическом ключе.

Для В. Сильвестрова отправными началами в музыке являются жанровость и интонационность, причем вторая оказывается, в конце концов, жанрово-обусловленной, но в значительно большем историческом времени - в значительно большем, а значит, более ответственном смысловом масштабе. Композитор не столько старается приобщить музыку к себе, к своим личностным композиторским попыткам, сколько открывает возможности приобщения к ней вплоть до «ухода» от творческого эгоцентризма.

Среди основных жанрово-семантических прототипов, привлекаемых Сильвестровым, можно назвать песенную кантилену, кантилену классическую (моцартианского образца), аккордово-хоральные построения, активные перемещения внутри фактуры, напоминающие о жанрах импровизационной природы - фантазиях, токкатах, об общих формах движениях с присущей им механистической ровностью, обобщенную танцевальность, скерцозно-танцевальное начало, фантастическое скерцо (внутри которого, в частности, могут реализоваться и контрастные построения фактуры). Названные жанрово-семантические прототипы можно встретить не только в музыке В. Сильвестрова. Более того, для него важно именно то, что многие из них он «берет» из уже сложившегося опыта их интерпретации, из «рук» какого-либо иного автора. Поэтому в музыке В. Сильвестрова очень часто явственно слышны «шубертовское», «купереновское», «гайдновское», «моцартианское», «прокофьевское», «шостаковическое» и некоторое другое.

Валентин Сильвестров дал этой новой композиторской позиции очень ясное обоснование. В одном из своих интервью он указал на то, что никогда не занимается буквальными историческими реконструкциями музыки или умозрительными экспериментами. В. Сильвестров признает два основных рода музыки: исполнительскую и авторскую музыку, причем исполнительскую отождествляет с 
анонимным и универсальным началом в музыке, а вторую - с автономным, личностно-композиторским. При этом он утверждает, что анонимное, универсальное как «общая земля» должно присутствовать в любом композиторском опусе. «Чистая индивидуальность, пишет В. Сильвестров, - постоянно демонстрирующая себя, может обернуться абсурдом» $[10,13]$. В музыке В. Сильвестров стремится открыть неуничтожимые, то есть постоянно присутствующие моменты; по его словам, «мир светится сквозь музыкально-телесные формы - интонацию, жанровость» [10, 13].

В музыке В. Сильвестрова, прежде всего, привлекает позитивный смысл, чистота, чувство жизни, духовной породненности людей и эпох. Потому для него сохраняют необычайную важность мелодические возможности становления и развития музыки. Композитор сам признается в том, что он пытается строить форму как мелодию; во всяком случае, для В. Сильвестрова важны мелодико-кантиленные свойства музыкального языка и те европейские стили, которые связаны с развитием мелодического мышления.

Валентина Сильвестрова трудно назвать неоклассиком, хотя весь он в диалоге с объективным, то есть с лежащим за пределами его личностного «я», опытом музыкального творчества. Он чрезвычайно субъективно, по-своему, как правило, ощущает дистанцию во времени и, отрицая ее, использует чужой стилевой опыт. Впрочем, никакой стилевой опыт, по мнению В. Сильвестрова, не может быть слишком чужим. Он пишет: «На каком бы языке ни говорить, любое произведение сильно не прямым смыслом, а иносказанием» [10, 14]. Поэтому В. Сильвестров открывает для себя возможность пользоваться «устаревшими фонемами», но произносит их как свои.

Загадка полистилистического метода В. Сильвестрова состоит в том, что он не столько создает дистанцию между «своим» и «чужим», сколько пытается подойти к нему поближе, стремится в этом диалоге найти новую близость, новую степень тождества. Такой метод полистилистики не подходит ни под одно из существующих определений видов полистилистики в интерпретации В. Холоповой (здесь имеется в виду типология полистилистики, предложенная данным музыковедом, в частности, выделение диффузной, коллажной и плюралистической полистилистики) и требует нового названия.

Мы предлагаем определение «иентробежная полистилистика» как наиболее точно отражающее особенности композиционных приемов В. Сильвестрова. Полистилистический диалог в музыке этого ав- 
тора осуществляется не только как диалог «своего-чужого», но и как «встреча» старого и нового - уже известного, даже традиционного, и неожиданного, индивидуализированного в смысловых значениях и композиционно-стилистической организации музыкальных образов. Однако новое - как собственная интонация автора, найденная им путем сложного взаимодействия жанровых и стилевых «знаков» музыки, - обнаруживает себя как обновление музыкальной памяти, то есть повторение-возобновление тех музыкальных идей, без которых невозможно представить себе ценностный комплекс музыкальной культуры. Интонационно-стилистическая новизна, авторизованность музыкально-драматургических концепций В. Сильвестрова оказывается иной языковой формой по сравнению с известными до него формами высказывания тех главных смыслов, к которым всегда обращено художественное сознание, которые являются постоянной стороной в эволюции художественного метода. Такие смыслы незаменимы; их можно только повторить - но так, чтобы два значения приблизились, обрели новую конкретность, новую жизненную силу. Возобновляемая вместе с такими смысловыми значениями, сохраняется и «жанровая Память» музыки, открывая свои новые полистилевые возможности.

\section{СПИСОК ЛИТЕРАТУРЫ}

1. Билык О. Просторово-часові аспекти формотворення у камерноінструментальній музиці Валентина Сильвестрова. Записки наукового товариства ім. Т. Шевченка. Праці музикознавчої комісії. Львів, 1993. Т. CCXXVI. C. $152-160$.

2. Жалейко Д. Китч и его трансформация в творчестве Валентина Сильвестрова: дис. канд. искусствоведения: спец. 17.00.03 / Харьков. нац. университет искусств им. И. П. Котляревского. Харьков, 2016. 205 с.

3. Зинькевич Е. Валентин Сильвестров. Musica Ukrainica: інтернет-журнал URL: http: //www.musica-ukrainica.odessa.ua/_a-zinkevich-silvestrov.html

4. Коханик И. Между полистилистикой и метастилем: о стилевых исканиях украинских композиторов на рубеже XX-XXI веков. Київське музикознавство: музикознавство у діалозі. К.: Дюссельдорф, 2010. Вип. 33. С. 102-115.

5. Коханик И. Слово как фактор стилеобразования в музыке В. Сильвестрова. Науковий вісник НМАУ ім. П. І. Чайковського. Слово, інтонація, музичний твір. Киев, 2003. С. 189-198.

6. Лунина А. Композитор - маленькая планета. К.: Дух і літера, 2013. C. $527-656$.

7. Нестъева М. Творчество Валентина Сильвестрова. Композиторы союзных республик: сб. ст. / сост. М. Нестъева. М.: Композитор, 1983. Вып. 1. C. $79-121$. 
8. Павлишин С. Сильвестров. В. Из серии творческие портреты украинских композиторов. К.: Музична Україна, 1989. 88 с.

9. Сальм А. Интенциональная динамика в фортепианных сонатах Валентина Сильвестрова. URL: http://www.gnesin-academy.ru/vestnikram/file/salm.pdf

10. Сильвестров В. Музыка - это пение мира о самом себе... Сокровенные разговоры и взгляды со стороны: Беседы, статьи, письма / автор статей, составитель, собеседница М. Нестьева. К., 2004. 264 с.

11. Сильвестров В., Пилютиков С. Дождаться музыки: лекции-беседы. По материалам встреч, организованных Сергием Пилютиковым. К.: Дух і літера, 2010. $367 \mathrm{c}$.

12. Чигарева Е. Полистилистика. Теория современной композиции. М.: Музыка, 2005. С. 431-449.

13. Холопова В. Специальное и неспециальное музыкальное содержание. - М.: Издательство МГК им. П. И. Чайковского, 2002. - 312 с.

14. Холопова В. Формы музыкальных произведений. Учебное пособие. СПб.: Лань, 1999. - 496 с.

\section{REFERENCES}

1. Bilyk O. (1993) Spatial-temporal aspects of forming in chamber-instrumental music by Valentin Sylvestrov. Notes of scientific society. T. Shevchenko. Works of musicology commission. Lviv, T. CCXXVI. 152-160. [in Ukrainian].

2. Zhaleiko D. (2016) Kitch and his transformation in the work of Valentin Silvestrov: Candidate's thesis. Kharkov [in Russian].

3. Zinkevich E. Valentin Silvestrov. Musica Ukrainica: online-magazine.URL: http: //www.musica-ukrainica.odessa.ua/_a-zinkevich-silvestrov.html [in Russian].

4. Kohanik I. (2010) Between polystylistics and metastyle: on style searches of Ukrainian composers at the turn of the 20th and 21st centuries. Kyiv Musicology: Musicology in Dialogue. TO.; Dusseldorf, Vip. 33. 102-115. [in Russian].

5. Kohanik I. (2003) Word as a factor of style in music V. Silvestrov. Scientific herald of NMAU im. P. I. Tchaikovsky. Word, intonation, musical composition. Kiev, 189-198. [in Russian].

6. Lunina A. (2013) The composer is a small planet. K.: Duh i Litera, 527-656. [in Russian].

7. Nesteva M. (1983) Creativity of Valentine Silvestrov. Composers of the Union Republics: Sat. Art. / comp. M. Nesteva. M.: Compositor, Vip. 1. P. 79-121. [in Russian].

8. Pavlishin S. (1989) Silvestrov. V. From a series of creative portraits of Ukrainian composers. K.: Musichna Ukraina [in Russian].

9. Salm A. Intentional dynamics in piano sonatas by Valentin Silvestrov. URL: http://www.gnesin-academy.ru/vestnikram/file/salm.pdf[in Russian].

10. Silvestrov V. (2004) Music is the singing of the world about oneself... Conversations and views from the side are hidden: Conversations, articles, letters / author of articles, compiler, interlocutor M. Nestieva. K. [in Russian]. 
11. Silvestrov V., Pilyutikov S. (2010) Waiting for music: lectures-conversations. Based on the materials of the meetings organized by Sergius Pilyutikov. K.: Duh i Litera. [in Russian].

12. Chigareva E. (2005) Polystylistics. The theory of modern composition. M.: Musica, 431-449. [in Russian].

13. Kholopova V. (2002) Special and non-special musical content. Moscva: Izdatelstvo MGK im. P. I. Tchaikovsky [in Russian]. sian].

14. Kholopova V. (1999) Forms of musical works. Tutorial. St.P: Lan [in RusСтаття надійшла до редакції 22.06.2016

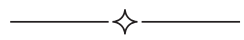

УДК 78.01(78.03, 78.05, 781.1, 781.2, 7.01, 7.06)

Таганов Олег Николаевич, кандидат искусствоведения, доцент кафедры философии и культурологии

Национального университета кораблестроения имени адмирала Макарова oltag@i.ua

\section{МУЗЫКАЛЬНЫЙ РЕМИКС КАК ФАКТОР ФОРМИРОВАНИЯ ФИЛОСОФИИ «РИНГТОННОЙ» КУЛЬТУРЫ}

Цель статьи - рассмотреть основные различия между ремиксом (использующим преимущественно классический музыкальный тематизм) и другими музыкальными жанрами похожей направленности, проанализировать его роль и место в формировании и функционировании современной «рингтонной» культуры. Методология: данное исследование опирается на культурологический, аксиологический, историографический и жанровый подходы. Научная новизна. Проблема современного развития музыкальных жанров в сфере легкой и популярной музыки поднимается в этой статье в конкретизированном рассмотрении жанра ремикса (главным образом классических тем и произведений). Выводы. Снижение аксиологических критериев при создании произведений в этом жанре по сравнению с подобными жанрами в прошлом обусловливает резкое падение музыкального вкуса и делает невозможной передачу и усвоение высоких художественных образцов музыки предшествующих эпох. С проблемой ускорения современной жизни и нехваткой времени для эстетичного и духовного саморазвития возникает возможность использования жанров типа ремикса как суррогата творческого поиска. Они формируют

(C) Таганов О. Н., 2016 